\title{
PSM Contribution to Democracy: News, Editorial Standards and Informed Citizenship
}

\section{Valuing journalism in a disposable news culture}

In an increasingly market-driven news environment, public service media (PSM) face growing pressure to justify the value of their journalism. After all, with online and social media, news has become more widely available and disposable, and can often be accessed instantly, at zero expense. Relying solely on advertisements for their funding, some newspapers are simply distributed for free in shopping centres and train stations. Like fast food, news has become a cheap and convenient commodity, accessible 24/7 online and even on the move.

But while news might be more freely available than ever before, the editorial standards of different outlets do not necessarily meet or satisfy people's expectations of what news should be in a properly functioning democracy. From exposing 'fake news' during elections, investigating data breaches at Facebook or reporting corruption, democracies rely on wellresourced newsrooms to inform citizens about what is happening in the world. If journalism as a commodity is being devalued and replaced by a fragmented supply of news and information, it may create an environment where news is cheap to consume but offers little democratic nourishment for advancing an informed or engaged citizenry.

At the same time, an ever-expanding range of media ostensibly serves citizens a menu of news that they can choose from. In a more deregulated media environment, the state no longer exercises the same degree of editorial oversight, allowing broadcasters greater freedom to innovate and set their own news agendas. And since market competition should in theory drive up standards, a more crowded and competitive media marketplace might help produce better quality journalism. So, for example, beyond broadcasting there are commercial print and online niche outlets such as The Guardian, ProPublica, The New York Times or Spiegel Online, which have market goals but fulfil the public service value of informing audiences about politics and public affairs. From that perspective, democracy could be enhanced by a shift from public-service to market-driven media systems. 


\section{Focus of the report: PSM vs commercial broadcast news}

Against the backdrop of a fast-changing and increasingly commercialised media landscape, PSM face a number of questions about their continued role and relevance. This report will examine the evidence about news produced by PSM and consider the implications for democracy in two ways.

First, it will draw on the latest academic scholarship to examine the evidence about whether PSM produce news that is distinctive from their market-driven rivals. Second, it will consider how informative PSM coverage is compared to their commercial competitors. It will assess the latest research to establish whether public or commercial media systems offer the most effective way of raising public knowledge about politics and public affairs.

The focus throughout is largely on broadcast media, since much of the research in academic literature analyses television news programming, in particular newscasts, which can be compared between PSM and more market-driven organizations, as well as cross-nationally (Cushion, 2012). While there are many types of broadcast programme that contribute to a well-informed citizenry, television newscasts continue to be a popular source of information in advanced Western democracies (Cushion, 2015; Cushion and Thomas, 2018). There are also a number of niche commercial print and online news outlets, as previously acknowledged, which have worked with PSM to expose corruption and which play a vital watchdog role. Comparatively speaking, however, many of these organizations do not have the size or reach of national PSM. In this sense, PSM are not the sole source of important news, but they remain one of the most significant because of the continued influence broadcasters have in most advanced Western democracies (Cushion and Thomas, 2018).

The findings will be discussed in light of the contribution PSM make in informing the citizenry and enhancing democratic debate.

Overall, the following questions will be answered:

- How can the quality of news between different media systems be assessed? Do PSM newsrooms produce news of higher editorial standards compared with commercial television news?

- Which media system most effectively raises people's understanding and knowledge of politics and public affairs? Do PSM help produce a more informed citizenry than commercial outlets? 


\section{Understanding distinctiveness and comparing news output}

The term 'distinctiveness' is used in this report to refer to whether PSM produce news of a higher editorial standard than commercial broadcast media. After all, one of many longstanding principles of public service media is to deliver what the market neglects, since PSM should in theory operate free from commercial pressures and influence. In remaining distinctive, this should not mean PSM cannot strive to be popular or only cover those areas that market-driven organizations fail to address. However, many PSM organizations have the difficult task of ensuring they remain widely supported by the public - who invest financially in the service - while also fulfilling public service obligations in areas such as news programming that may not attract as many viewers as entertainment-based shows.

So how can distinctive news be interpreted? There is a range of widely shared editorial values and standards that many journalists would subscribe to, such as reporting truthfully or accurately, being independent or impartial, and serving the public interest. But measuring how far these standards are met is both conceptually and empirically challenging. So, for example, what interests the public may not represent news in the public interest. As many legal disputes have shown, public-interest journalism is a subject of fierce debate.

In order to empirically compare how distinctive PSM is from commercial media, it is necessary to make value judgements about output that can be measured across media with some degree of precision. Since most news organizations strive to advance people's understanding of the world, one measure of distinctive news is tracking the agenda of issues routinely pursued. Above all, news aims to empower citizens in a democracy, encouraging them to make informed choices and judgements about social, economic and political issues. From informing voters about their policy options during an election campaign to explaining civic unrest or famine conditions in war-torn countries, the informational fuel supplied by news media is essential to the genesis of an informed citizenry.

Put simply, understanding the democratic value of news - such as tracking the informative agenda of daily news programmes - can help assess the quality of journalism produced by different media systems. As will now be explored, the intrinsic value of news can be measured and compared in a variety of ways. Needless to say, empirical studies of news cannot easily capture and quantify the democratic value of journalism, but the following studies will help paint a quantitative picture of PSM and commercial television news. 


\section{Is PSM distinctive from commercial television news?}

In The Democratic Value of News: Why Public Service Media Matter (Cushion, 2012), I examined over 250 studies that considered whether the editorial standard of PSM news was distinctive from commercial output. Most of the research was about European countries or the US because most English-language academic publications emanate from these parts of the world. Overall, the most conclusive comparative findings related to analysing news agendas in routine periods of time and during election campaigns. In both cases, the weight of evidence showed public service media was far more informative, which was measured by news being more likely to empower citizens in democracy, such as telling people about the policy choices of different political parties, rather than reporting celebrity gossip or crime stories.

Overall, this book established that there tended to be a higher proportion of 'hard' news in PSM, which addressed issues such as politics and international affairs, rather than 'soft' news, including crime or entertainment news. During election campaigns, PSM were also more likely to report policy issues than market-driven media, which often placed greater emphasis on game or strategy stories.

While studies analysing journalism over time have found news agendas generally shifting from 'hard' to 'soft' reporting, this was more pronounced on market-driven media. In effect, this meant PSM, most of the time, were more likely to supply a harder news agenda, reporting more domestic issues or international affairs, which offer policy or analytical information. Curran et al.'s (2012) study of nine countries broadly found this pattern of coverage across a range of different countries. In other words, a broadly distinctive pattern is that public service bodies tend to supply a higher volume of hard news than market-driven media. While not all PSM produced more hard news than commercial media, overall most did and when they did not in all but two cases hard news accounted for more than $60 \%$ of the agenda. Meanwhile, Reinemann et al.'s (2016) analysis of 160 outlets across 16 countries found harder news emanated from public service media than from commercial television networks, broadsheet newspapers and websites. 


\section{Is PSM distinctive from commercial television news during election campaigns?}

Second, during election campaigns - a key point in any democracy - PSM focus more on issues and policy implications than market-driven media. That might involve, for example, scrutinizing the manifesto promises of parties or independently examining how credible they are. Commercial media, by contrast, tended to report more game or strategy-type stories, which centre on who's up or down in the polls as well as the campaigns and personalities of the electoral contest. PSM also covered low-key campaigns, such as local or European elections, which were often ignored by market-driven media. Political scientists have labelled these 'second-order' elections, since they are not necessarily viewed as being as significant as general or presidential elections. But given local and European bodies exercise considerable power, from decisions about the environment and consumer rights to social care and collecting rubbish, reporting their election campaigns and scrutinizing the issues citizens are voting on is vital to the health of a democracy.

As Chart 1 shows, while all UK television news bulletins widely reported the 2015 and 2017 general election campaigns, it was the $\mathrm{BBC}$ - a public service broadcaster - that consistently dedicated time to covering both the local and EU election campaigns. So, for example, whereas Channel 5 's $5 \mathrm{pm}$ bulletin spent just $1.2 \%$ and $1.0 \%$ of its total news agenda covering the 2009 and 2013 local and/or EU election campaigns, on the BBC News at Six it accounted for $6.2 \%$ and $4.7 \%$ respectively. Broadly speaking, most official campaigns lasted approximately six weeks, which is the period of time analysed, including weekends.

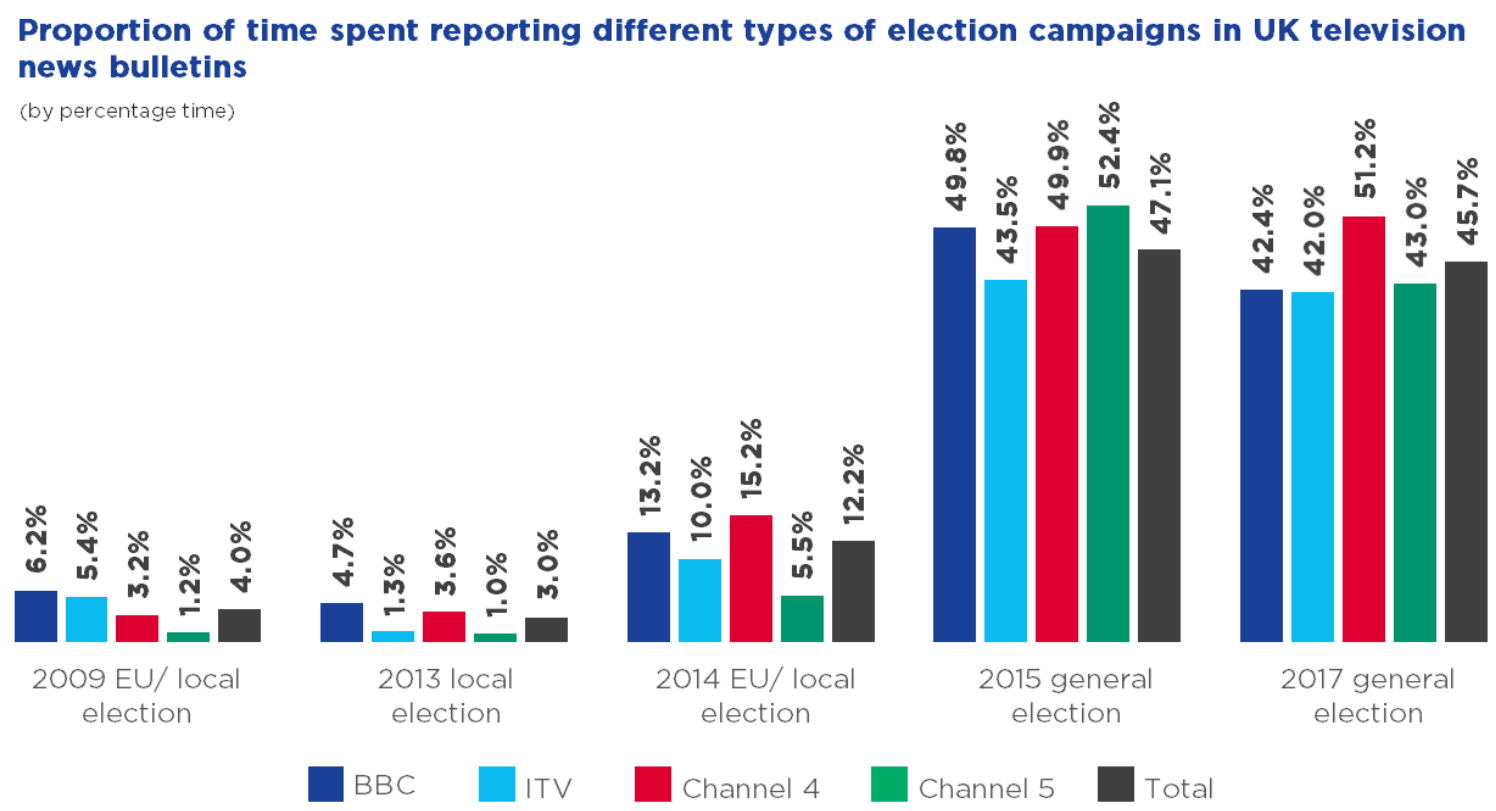

Source: adapted from Cushion (2018).

In the UK there are also commercial public service broadcasters, which each operate with different regulatory obligations. Channel 5 - the broadcaster subject to the lightest regulations in news programming - produced the fewest stories about the local and EU election campaigns. 
Although the quality of news can differ between public service media, the very presence of a well-resourced and regulated PSM within a country can also help elevate the standards of journalism more widely (Cushion et al., 2012). Or, put more succinctly, well-resourced PSM help promote a race to the top in news standards within a mixed media system. So, for example, a market-driven news channel, Sky News, has resisted any pressure to conform to the more US-style of Fox News not just because of the UK's strict regulatory guidelines but arguably thanks to the professional commitment and culture of journalists who want to report accurately and impartially (Cushion and Lewis, 2009). While Fox's partisan approach to news reporting has proven highly successful and influential in the US, and has been emulated by other US news channels such as MSNBC, the UK's public service culture and regulatory framework have meant its sister channel, Sky News, has not become 'Foxified'.

In the US, by contrast, PSM are not well funded or widely watched. The US is dominated by a market media-system and subject to limited regulation that would encourage fair and balanced journalism. Unlike most other democracies, for example, broadcasters do not have to follow rules about impartiality, which is why many news channels, such as Fox News and MSNBC, have clear partisan agendas. Compared to the UK's commercial broadcasters, which have some public service obligations, wholly market-driven news media do not have to meet specific editorial standards or obligations. So, for example, the US's main network news bulletins - ABC, CBS and NBC - all schedule their news at the same time $(6: 30 \mathrm{pm})$, whereas in the UK's hybrid media system a regulator - Ofcom - oversees scheduling to ensure audiences have a plurality of news sources to watch at different times of the day.

The balance and agenda of the US's market-driven media compared to the UK's commercial public service media can be shown in coverage of the 2016 and 2017 US and UK presidential and general election campaigns. In the three main US network evening bulletins, there was barely any news about the presidential candidates' policy positions supplied throughout 2016. As one study found, between January 1, 2016, and October 21, 2016, just $8 \%$ of the news agenda on $\mathrm{ABC}$ and $\mathrm{NBC}$ in this period of time was spent reporting stories that focused on candidates' policy positions rather than other aspects such as personal issues or conflicts, although that was slightly higher - 16\% - on CBS (adapted from Boehlert, 2016). There was also a clear imbalance in the time allotted to presidential candidates to articulate their views during the campaign. Tyndall's (2016) study of network television news, for example, revealed coverage of Donald Trump's campaign was double that of Clinton's - 1,144 minutes compared to 506 minutes - throughout the entire of year of 2016 (see Chart 2). 


\section{Comparative coverage of election campaigns on US network news during 2016}

(minutes of coverage)
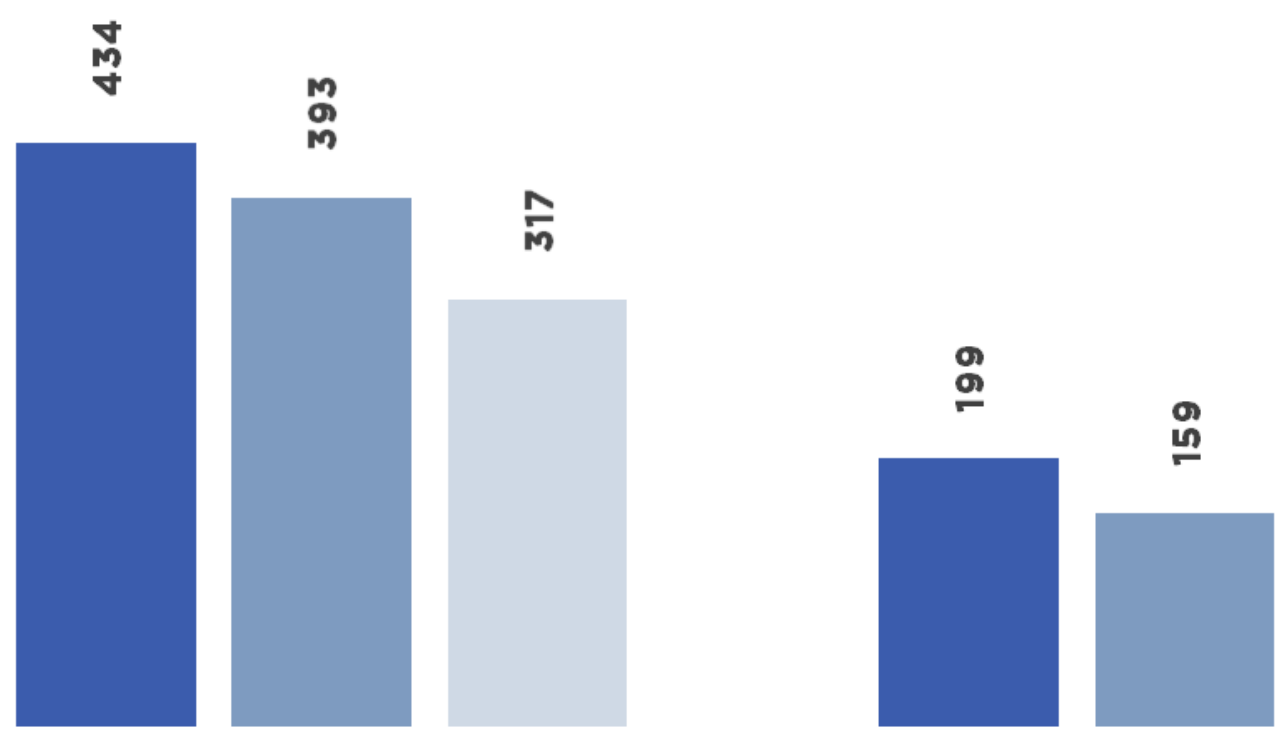

$\stackrel{\text { q }}{\mathbf{q}}$

Donald Trump campaign

Hillary Clinton campaign

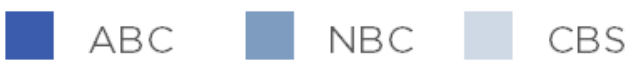

Source: adapted from Tyndall (2016).

By contrast, as Chart 3 demonstrates, the UK's commercial public service media and marketdriven news channel reported far more policy coverage, while Chart 4 shows coverage was, broadly speaking, more balanced between the main political parties. 
Proportion of airtime about policy issues on television news bulletins during the 2015 and 2017 UK general election campaigns

(by percentage time)
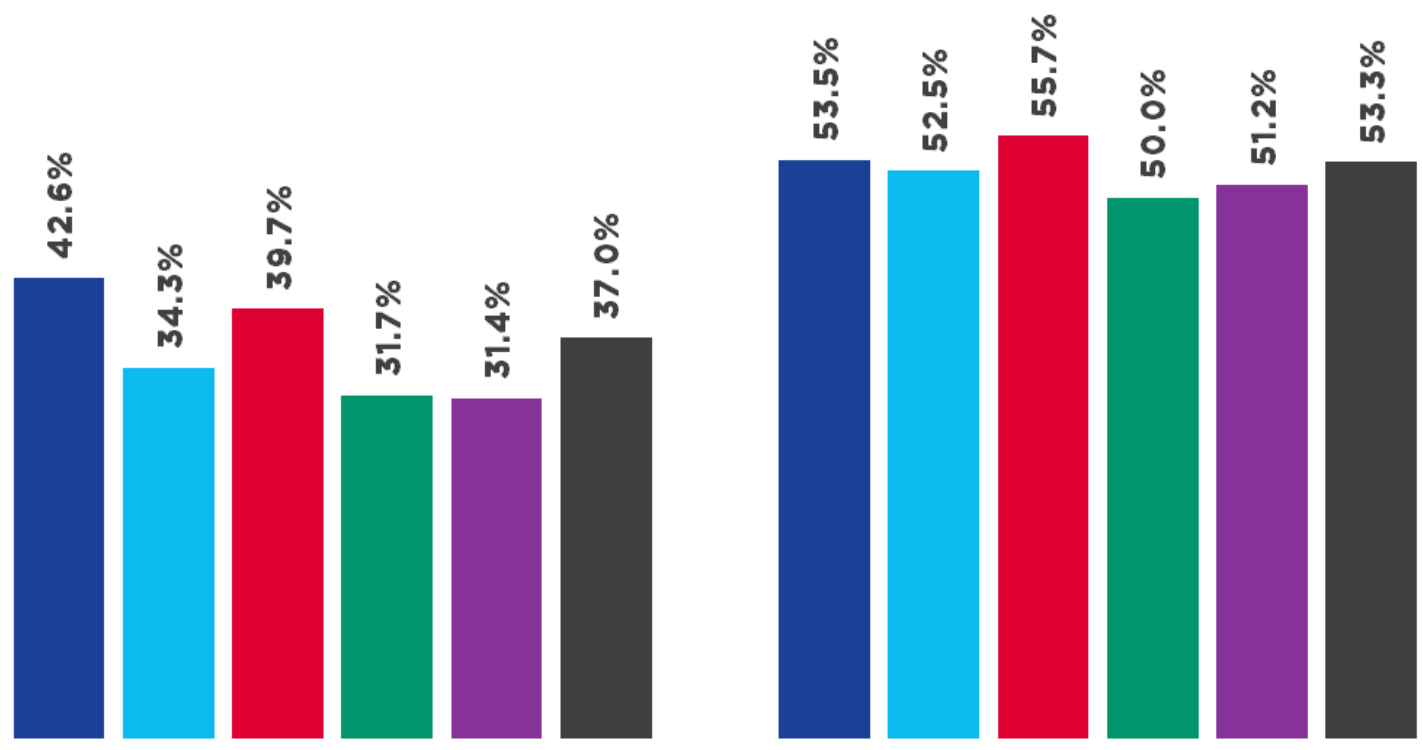

2015

$\square$ BBC $\quad$ ITV

Channel 4

Channel 5

2017

Sky News

Total

Source: adapted from Cushion et al. (2016) and Cushion (2018).

Proportion of airtime for political parties on UK television news during the 2017 UK general election

(by percentage time)
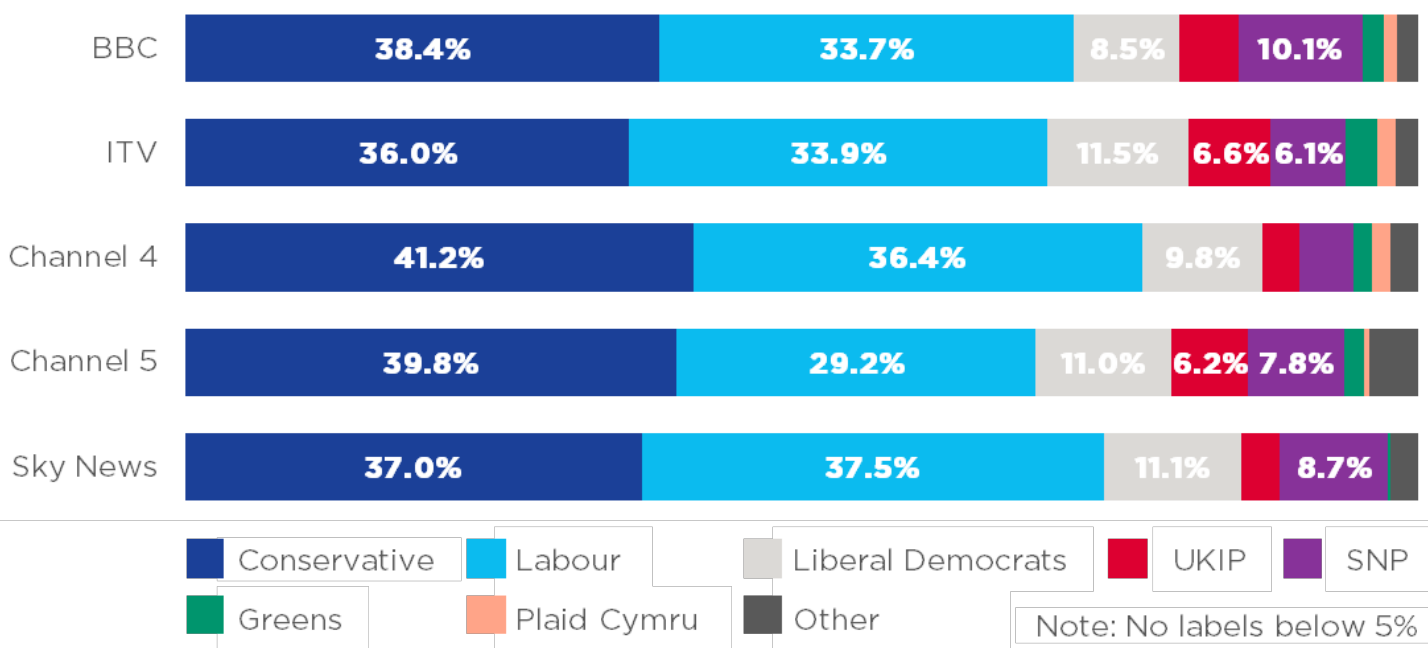

Source: adapted from Cushion (2018). 


\section{The future of news and PSM limitations}

Most of the comparative research about public and market-driven media systems is based on broadcast news coverage. However, there is a growing body of evidence about online news that reinforces the conclusion that PSM supplies distinctive news from market-driven media. As Humprecht and Esser's (2016: 16) comprehensive study of news content in 48 websites in six countries - France, Italy, Germany, Switzerland, the UK and US - concluded: "Strong commercialization seems to restrict the exploitation of online journalism's digital potential to a certain degree. Moreover, media systems with high expenditures in public service broadcasting (e.g. Great Britain, Germany) have more sophisticated online news providers than systems with marginalized public media". Their assessment was based on considering each outlet's transparency in linking to external sources, documents or websites; the degree of background information, such as graphics, news boxes, graphs, maps or animations; and whether there was any follow-up communication in forums or chats (Humprecht and Esser, 2016: 506).

In broader terms, the study argued that since many public service media have invested in online news, they demonstrated its democratic value by producing news that serves citizens with high-quality journalism. While there is fierce competition between PSM and commercial broadcasters in online news and new interactive technologies, studies examining content show the former is producing news distinctive from market-driven media.

At the same time, PSM should not be immune to criticism. The impartiality of PSM has often be called into question in political reporting, where the state may exercise too much control, compromising the ability for broadcasters to act independently or remain impartial. This is a form of elite control, where even well-intentioned PSM attempt to deliver a public good but remain wedded to institutional relationships and forms of indirect political pressure and scrutiny that can influence news choices and judgements (Freedman, 2018). This may be a symptom of their relationship with the government of the day, and how their current and future funding are organized. There are potentially ways PSM can be restructured to help create more independent newsgathering and journalism, where the state is more detached from funding decisions and a more democratic system of governance is established (see, for example, Media Coalition Reform, 2018).

Nevertheless, the evidence presented overall in this report so far shows that public service media tend to supply more serious and balanced coverage of politics and public affairs than market-driven media systems. In countries with a hybrid media system, where public-private obligations overlap, the very presence of public service obligations can help raise the editorial standards of journalism. Or, to put it another way, PSM help mitigate the costs of free market failure. But while PSM may be more informative than their commercial competitors, which media system most effectively raises people's knowledge about politics and public affairs? 


\section{Towards an informed citizenry: Does PSM more effectively raise public knowledge than commercial media?}

The media can make a significant contribution to democracy by creating more informed citizens, enhancing voters' knowledge and understanding of issues. However, this is contingent on the quality of information supplied by different media, which can not only inform citizens but misinform them about politics and public affairs.

Since most countries have an increasingly fragmented and hybrid media, where people interact and access news across multiple platforms, it is difficult to isolate the influence of one media system over another. Interpreting causality - establishing a direct relationship between media and audiences - is methodologically complex. After all, knowledgeable or interested news viewers may turn to more informative news outlets, meaning the cause is not media coverage but wider and pre-existing influences. In other words, there are many factors at play when interpreting public knowledge, from levels of education and social welfare to cultural norms, such as interest in or engagement with politics within different countries.

However, after taking into account many external factors that make and shape people's knowledge and understanding of issues, a growing body of research has identified that PSM helps create more informed citizens than market-driven media.

So, for example, Soroka et al.'s (2013) survey of six countries - Canada, Italy, Japan, Norway, the UK and South Korea - found public service television news viewing generally enhanced people's knowledge about public affairs. However, this varied according to how broadcasters were financed, audience share and the relative independence of each organization. In other words, public service media were less likely to raise people's knowledge about public affairs if they were reliant on commercial income, were not widely watched or listened to, or if the state had an influence on the editorial content of news. The study also discovered that in the country where state interference in public broadcasting was most evident, watching public service television did not effectively enhance people's knowledge.

Curran et al.'s (2009) content analysis of television news and survey of four countries - the US, UK, Norway and Finland - revealed the latter two countries were most knowledgeable about public affairs. The knowledge gap was most striking between uninterested political news viewers in the US compared to European countries, which is due - they argued - to citizens having regular access to reliable sources of news supplied most prominently by PSM. They concluded empathically: "media provision of public information does matter, and continued deregulation of the broadcast media is likely, on balance, to lead to lower levels of civic knowledge". Similarly, Iyengar et al.'s (2009) comparative survey of US and Swiss audiences discovered "dark areas of ignorance" among Americans, which they explained by the limited supply of international news produced by US market-driven media. 


\section{The role of PSM in an increasingly partisan news environment}

Moreover, the rise of partisan news channels in the US has meant people are increasingly turning to outlets that reinforce their own ideological beliefs, a behaviour known as partisan selective exposure. Bos et al.'s (2016: 10-11) survey of people in the Netherlands found the presence of public service media mitigated partisanship because they played "a unifying, and nation-binding role... a strong public news provision...is an important condition to avoid the US situation where the public sphere appears to have become different public spheres". Put another way, the presence of public service media appears to challenge the growth of filter bubbles or echo chambers, which are concepts used to describe people insulating themselves from news they do not agree with. The wider consequences of PSM thus help ensure more citizens receive impartial news, covering a wide range of topics rather than being exposed to information that ideologically aligns with people's own beliefs.

Over recent years, academics have begun to more closely interpret studies about the content of news in light of people's responses to survey-based questioning. So, for example, a study of how European integration was framed in Dutch media found some news topics, such as coverage of conflict, increased the likelihood of people voting and knowledge about the issue. In their view, "it is not sufficient to rely on exposure measures and to merely speculate about media content" (de Vreese and Boomgaarden, 2006: 333). Instead, they argued, it is necessary to more carefully consider the nature of coverage across different programmes together with interpreting audiences' engagement with and knowledge about different issues.

A four-wave survey in Swedish public and commercial news programming examined people's knowledge in three contexts: the 2014 General Election, the EU Parliamentary Election and in a non-election period the same year. In each case, exposure to PSM raised people's understanding of key issues, contributing toSweden's democratic health as more people may have cast a more informed vote at the ballot box. When considering the degree to which different programmes' impact on people's understanding of politics, the study established certain public service formats enhanced knowledge to a greater degree. As the author concluded: "knowledge effects are stronger for one public service TV news show than for the other. This indicates that it is not ownership per se that is decisive. The format and the content also matter" (Strömbäck, 2017: 13; emphasis added).

Goidel et al. (2017) drew on survey data in the US, Germany, Sweden and the Netherlands to explore the relationship between television viewing and support for democratic ideals. They concluded that because citizens were being better informed by public service news, it "translates into a greater appreciation for democratic governance as reflected in the importance individuals attach to living in a democracy, the value they place on a democratic political system, and the rejection of authoritarian alternatives" (Goidel et al., 2017: 850-1). By contrast, in more market-driven media systems, such as in the US, "television news is not associated with democratic attitudes but is associated with support for authoritarian alternatives (a strong political leader or military rule)" (Goidel et al., 2017: 851). While they acknowledged both the political system and economic context in different countries help shape people's perceptions of democratic ideals, the democratic attitudes measured in the survey were cross-nationally consistent across television news but not when exposed to other types of media. 
Over recent years, people have been relying more on news beyond of television - from social media to online websites and blogs. Many public service broadcasters have invested heavily in online news or social media (Sehl et al., 2016), producing high-quality content (Humprecht and Esser, 2016). There is limited research about how effective different media systems are in informing people across new platforms and content providers, such as Facebook and Twitter.

In a media environment with increasingly more choice of news sources, PSM play a critical role in what is known as incidental learning. Simply put, this means people learning from the news almost by accident because they are more likely to encounter information supplied by PSM, giving them opportunities to acquire knowledge they may not have been exposed to in a heavily market-driven systems. In the US, for example, there is plenty of news available but it is often ghettoised or politicised. In many countries with better resourced PSM, by contrast, people are more likely to be exposed to news with high editorial standards on broadcast, online or social media platforms. 


\section{Conclusion: the need for PSM in an increasingly commercialised media landscape}

At a time when concerns are mounting about fake news and disinformation, ensuring news is delivered with high editorial standards is essential to sustaining a well-functioning democracy. News after all can empower citizens by providing them with the informational fuel to understand and learn about politics and public affairs in their democracies. But while the range of news sources has increased over recent decades across broadcast, online and social media platforms, the quality of news can markedly differ across media systems crossnationally.

Comparing output across public service and market-driven media, the weight of evidence shows it is the former that is more likely to report news that has democratic value. In an increasingly commercialised media environment, this demonstrates PSM provide a valuable and distinctive news service by supplying news that better enhances people's understanding of politics and public affairs, leading to more knowledgeable citizens. In other words, if the health of a democracy is measured by how well its citizens are informed, PSM play a crucial role in telling people what is happening in the world.

However, media systems are not uniformly the same across countries; regulatory environments can create private media that deliver public service programming. Empirical studies drawn on throughout this report have also established that media with some public service obligations tend to produce news of higher editorial standards than entirely marketdriven media. Indeed, even the very presence of a well-resourced public service media within a country can impact on the wider editorial standards of journalism, such as informing people accurately and impartially about events.

In exploring the relationship between media systems and public knowledge, surveys have consistently shown that PSM, above all, most effectively raise people's knowledge and understanding of politics and public affairs. This was most apparent among widely consumed and well-funded public service media, which had the most freedom to operate independently without editorial interference. More generally, it was found that PSM play an important role in preserving democratic ideals and remaining impartial or objective in an increasingly partisan media environment.

As more people are exposed to dubious or politicised information on sites such as Twitter and Facebook, PSM offer reliable and credible news that not only serves the needs of individuals but benefits entire democracies, since people can act more rationally as citizens when they have access to accurate news and information.

As the commercial media landscape expands in many countries, the temptation for already cash-strapped governments could be to cut funding for PSM and let the market fill the gap. However, the evidence overwhelmingly shows that PSM not only produce distinctive news with high editorial values, they are also best equipped to inform people about the world. In other words, public policy-making about media systems has profound effects on the health of any democracy. As Soroka and colleagues (2013: 738) succulently put it, "governments' decisions about funding for public broadcasters seem in many cases to be very much like decisions about just how well informed their citizens will be". 
The evidence amassed throughout this report points to some clear conclusions about the role of PSM. Above all, they make a profound contribution to many democracies by raising editorial standards and citizen's knowledge about what is happening in the world. This body of research needs to be more effectively communicated to relevant stakeholders to persuade legislators about the continued value of funding and safeguarding PSM.

In an era of media proliferation, the evidence not only shows PSM produce news that is distinctive from market-driven broadcasters, but also news that has a higher democratic value. In so doing, PSM make a significant contribution to the health of many democracies, acting as an important information source about politics and public affairs for many people, and empowering citizens to engage and participate in society more generally. Just as media audiences are fragmenting across a range of market-driven platforms, PSM continue to offer a distinctive democratic service, not just for some audiences but for all citizens in a democracy.

\section{References}

Boehlert, E. (2016) 'The media isn't for Hilary Clinton: her emails have been covered more than all policy proposals', Salon, 3 November, Salon Media Group.

https://www.salon.com/2016/11/03/the-media-isnt-for-hillary-clinton-her-emails-have-beencovered-more-than-all-policy-proposals/

Bos, L., Kruikemeier, S. and de Vreese, C. (2016) 'Nation Binding: How Public Service: Broadcasting Mitigates Political Selective Exposure', PLOS ONE 11(5): 1-11. http://journals.plos.org/plosone/article?id=10.1371/journal.pone.0155112

Curran, J., Iyengar, S., Lund, A. B. and Salovaara-Moring, I. (2009) 'Media Reporting, Public Knowledge and Democracy: A Comparative Study', European Journal of Communication 24 (1): 5-26.

Curran, J. et al. (2012) 'Media system, public knowledge and political engagement: an 11nation study', unpublished material.

Cushion, S. (2012) The Democratic Value of News: Why Public Service Media Matter. Basingstoke: Palgrave Macmillan.

Cushion, S. (2015) News and Politics: The Rise of Live and Interpretive News. London: Routledge.

Cushion, S. (2018) 'Questioning the (conventional) wisdom of political reporting: Rethinking vox pops and interpretive journalism in five UK election campaigns (2009-2017)', forthcoming.

Cushion, S. and Lewis, J. (2009) 'Towards a 'Foxification' of 24-hour news channels in Britain? An analysis of market-driven and publicly funded news coverage', Journalism: Theory, Practice and Criticism 10(2): 131-153. 
Cushion, S., Lewis, J. and Ramsay, G. N. (2012) 'The impact of interventionist regulation in reshaping news agendas: A comparative analysis of public and commercially funded television journalism', Journalism 13(7): 831-849.

Cushion, S. and Thomas, R. (2018) Reporting Elections: Rethinking the Logic of Campaign Coverage. London: Polity.

Cushion, S., Thomas, R., Kilby, A., Morani, M. and Sambrook, R. (2016) 'Interpreting the media logic behind editorial decisions: Television News Coverage of the 2015 U.K. General Election Campaign', International Journal of Press/Politics 21(4): 472-489.

de Vreese, C. and Boomgaarden, H. (2006) 'News, Political knowledge and participation: the differential effects of news media exposure on political knowledge and participation', Acta Politica 41(4): 317-341.

Freedman, D. (2018) '"Public Service" and the Journalism Crisis: Is the BBC the Answer?', Television and New Media, OnlineFirst.

http://journals.sagepub.com/doi/full/10.1177/1527476418760985

Goidel, K., Gaddie, K. and Ehrl, M. (2017) 'Watching the News and Support for Democracy: Why Media Systems Matter', Social Science Quarterly 98 (3): 836-855.

Humprecht, E. and Esser, F. (2016) 'Mapping digital journalism: Comparing 48 news websites from six countries', Journalism: Theory, Practice and Criticism, OnlineFirst.

Iyengar, S., Hahn, K. S., Bonfadelli, H. and Marr, M. (2009) "'Dark areas of ignorance" Revisited: Comparing International Affairs Knowledge in Switzerland and the United States', Communication Research 36(3): 341-358.

Media Coalition Reform (2018) Draft Proposals for the Future of the BBC. http://www.mediareform.org.uk/wp-content/uploads/2018/03/MRC flyer 20180312 WEB$\underline{1 . p d f}$

Reinemann, C., Stanyer, J. and Scherr, S. (2016) 'Hard and Soft News'. In de Vreese, C., Esser, F. and Hopmann, D. (eds.) Comparing Political Journalism. London: Routledge. Strömbäck, J. (2017) 'Does Public Service TV and the Intensity of the Political Information Environment Matter?', Journalism Studies 18(11): 1415-1432.

Sehl, A., Cornia, A. and Nielsen, R. K. (2016) Public Service News and Digital Media. Oxford: Reuters Institute for the Study of Journalism, University of Oxford.

Soroka, S., Andrew, B., Aalberg, T., Iyengar, S., Curran, J., Coen, S., Hayashi, K., Jones, P., Mazzoleni, G., Rhee, J. W., Rowe, D. and Tiffen, R. (2013) 'Auntie Knows Best? Public Broadcasters and Current Affairs Knowledge', British Journal of Political Science 43(4): 719-739. 
Tyndall, A. (2016) Year in Review, Tyndall Report.

http://tyndallreport.com/yearinreview2016/ 